\title{
Progressive neurological dysfunction during latent HIV infection
}

\author{
Johannes Jakobsen, Torben Smith, Johannes Gaub, Susanne Helweg-Larsen, Werner Trojaborg
}

Departments of Clinical Neurology, and Infectious Diseases, University Hospital of Copenhagen, Rigshospitalet, DK-2100 Copenhagen $\emptyset$, Denmark Johannes Jakobsen, PHD, senior registrar

Torben Smith, MD, senior registrar

Johannes Gaub, PHD, consultant in infectious diseases

Susanne Helweg-Larsen, $\mathrm{MD}$, research fellow Werner Trojaborg, PHD, consultant clinical neurophysiologist

Correspondence and Smith, Department of Clinical Neurophysiology.

$\operatorname{BrMed} \mathcal{f} 1989 ; 299: 225-8$ Neurophysiology, requests for reprints to: $\operatorname{Dr} T$

\begin{abstract}
Objective-To determine whether the delayed conduction through the spinal cord and peripheral nerves seen in patients with AIDS is related to infection with HIV or to the presence of an immunodeficient state.
\end{abstract}

Design-Two year prospective follow up study of electrophysiological measurements in subjects positive for HIV antibody but without AIDS.

Setting-HIV screening clinic and clinical departments in a university hospital in Copenhagen, Denmark.

Subjects-Twelve homosexual men positive for HIV antibody who had not developed AIDS.

Results - Eight latencies were measured: from the ankle to $\mathrm{T} 12$, the wrist to $\mathrm{C} 7, \mathrm{~T} 12$ to the cerebral cortex, $\mathrm{C} 7$ to the cerebral cortex, the ankle to the gluteal crease (tibial nerve), the gluteal crease to T12, the wrist to Erb's point (median nerve), and Erb's point to C7. Spinal latencies increased in all subjects at $\mathrm{C} 7$ by a mean of $4 \cdot 2 \%($ SE $0.9 \%)$ and in all except one at T12 by a mean of $5 \cdot 5 \%(1 \cdot 0 \%)$. The conduction time from the gluteal crease to $\mathrm{T} 12$ was increased by a mean of $32.0 \%(5.0 \%)$ whereas that in the median and tibial nerves by only $5 \cdot 6 \%(1.0 \%)$ and $2 \cdot 2 \%(2 \cdot 2 \%)$ respectively.

Conclusions-A mild and slowly progressive peripheral neuropathy of the axonal type and a more severe progressive myelopathy or myeloradiculopathy occur concomitantly with early HIV infection, possibly as the result of a direct neurotropic action of HIV.

\section{Introduction}

Opportunistic infections and neoplasms of the brain are well known secondary complications of AIDS. As well as these dramatic neurological manifestations, more insidious and slowly developing disorders occur in a large proportion of patients with AIDS, including peripheral neuropathy and vacuolar myelin degeneration of the long tracts of the thoracolumbar part of the spinal cord. ${ }^{1-7}$ Similar disorders also develop in subjects who are positive for HIV antibody and have a competent immune system, but systematic clinical and electrophysiological studies are few. ${ }^{8}$

Among 23 unselected Danish patients with AIDS most showed delayed conduction through the thoracolumbar spinal cord and also a mild slowing of conduc-

TABLE I-Clinical and immunological data at start of study and after two years in 12 men positive for HIV. Values are means $(S E)$ unless stated otherwise

\begin{tabular}{|c|c|c|c|c|c|c|c|c|}
\hline & \multirow{2}{*}{$\begin{array}{l}\text { Body weight } \\
(\mathrm{kg})\end{array}$} & \multicolumn{5}{|c|}{ Stages of HIV infection ${ }^{10}$} & \multirow{2}{*}{$\begin{array}{c}\text { No of } \\
\text { lymphocytes } \\
\left(10^{4} / 1\right)\end{array}$} & \multirow{2}{*}{$\begin{array}{c}\text { No of } \\
\mathrm{T}_{+} \text {cells } \\
\left(10^{\circ} / 1\right)\end{array}$} \\
\hline & & I & II & III & IVB & IVC & & \\
\hline $\begin{array}{l}\text { Start } \\
\text { After } 2 \text { years }\end{array}$ & $75 \cdot 4(3 \cdot 9)$ & 1 & 7 & 2 & 1 & 1 & $\begin{array}{l}3.0(0.3) \\
1.9(0.1)^{\star}\end{array}$ & $\begin{array}{l}0.85(0.12) \\
0.42(0.04)^{\star}\end{array}$ \\
\hline After 2 years & $75 \cdot 0(3 \cdot 6)$ & 0 & 4 & 3 & 3 & 2 & $1 \cdot 9(0 \cdot 1)^{\star}$ & $0.42(0.04)^{\star}$ \\
\hline
\end{tabular}

${ }^{\star} \mathrm{p}<0.0001$ tion in peripheral nerves. ${ }^{9}$ To examine whether these conduction defects were related to the HIV infection or occurred when the patient's immune system became deficient we studied 15 men who were positive for HIV antibody but had not developed AIDS. ${ }^{8}$ Conduction in peripheral nerves was found to be normal but a minimal, significant delay was recorded over the lumbar spinal cord at the twelfth thoracic vertebra. We report the clinical and electrophysiological results of a two year follow up study in the same group of men, of whom none had developed AIDS.

\section{Patients and methods}

Fifteen homosexual men positive for HIV antibody had been recruited from the HIV screening clinic at the department of infectious diseases at this hospital for a clinical and electrophysiological study in $1986 .{ }^{8}$ During follow up two years later 12 agreed to be re-examined; one had died of a progressive neurological disorder with ascending spastic paresis and two refused to participate. None drank alcohol or had drug treatment daily or abused recreational drugs.

The presence of HIV antibody was confirmed by western blot analysis during 1985 or 1986 . The time of seroconversion was unknown. The numbers of $\mathrm{T}_{4}$ cells were determined by direct immunofluorescence with monoclonal antibodies.

The same questionnaire on neurological symptoms was completed in 1986 and 1988, and an examination with special attention to the strength and coordination of the legs was performed on both occasions. To assess subclinical leg ataxia we measured the patients' ability to hit a square target with the foot, their precision in drawing horizontal lines between two vertical lines, and their deviation in copying a circle. The vibratory perception threshold was determined by using a biothesiometer.

For the electrophysiological study of evoked somatosensory potentials the same techniques were applied by the same technicians in 1986 and 1988 . Stimuli of $0 \cdot 2 \mathrm{~ms}$ that were 1.5 times above motor threshold were given at a frequency of $2 \mathrm{~Hz}$ and the potentials evoked averaged. Potentials were recorded with needles at the gluteal crease, at $\mathrm{T} 12$, and over the cortical area representing the foot after stimulation of the tibial nerve at both ankles. The median nerve was stimulated at both wrists and the potentials recorded in supraclavicular fossa (Erb's point), at C7, and over the cortical area representing the hand. Conduction distances were measured with a tape measure.

Only the eight electrophysiological variables that are routinely measured in our laboratory were examined -that is, the latencies of the well characterised negative peaks at $\mathrm{T} 12, \mathrm{C} 7$, and at the cortical areas corresponding to the foot and hand and the latencies of the positive peaks at the gluteal crease T12, Erb's point, and C7. The mean values of the intraindividual changes in latency during the two years of follow up 
were evaluated statistically by paired $t$ tests with the level of significance at $0 \cdot 005$. The clinical data, white cell counts, and correlation tests were examined statistically by unpaired or paired $t$ test with a 0.05 level of significance. Values are means and standard errors or means and $95 \%$ confidence intervals.

\section{Results}

Clinical and immunological data on the 12 patients studied in 1986 and 1988 are shown in table I. The age range at the start of the study was 21 to 43 (mean 36), the mean height $178(2) \mathrm{cm}$ and the recognised median duration of HIV infection 7 months (range 1-23 months). The clinical stage of HIV infection ${ }^{10}$ progressed from I or II to IVB or IVC in three subjects and from II to III in one. In eight subjects the clinical stage remained unchanged. There was no change in mean body weight, and the general condition of the subjects was good. Lymphocyte and $\mathrm{T}_{4}$ cell counts decreased in all except one subject $(p<0 \cdot 0001)$, whose count was unchanged.

Two patients had painful dysethesias in 1986, and two others developed acroparesthesias during the study. Muscular performance, measures of subclinical leg ataxia, position sense, and the discrimination of two points remained unchanged. One subject developed hyperactive patellar reflexes and ankle jerks and lost his abdominal reflexes. The vibratory perception threshold of the index finger was unchanged whereas that of the big toe tended to increase $(6 \cdot 0(0 \cdot 4) v 7 \cdot 0$ $(0 \cdot 6) ; \mathrm{p}=0 \cdot 05)$.

Table II shows the mean latencies of the negative peak of the evoked potentials at T12 and C7 and at the cerebral cortex from $\mathrm{T} 12$ and $\mathrm{C} 7$ at the start of the study and after two years. At T12 and $\mathrm{C} 7$ the latencies increased by $5 \cdot 5 \%(3 \cdot 2 \%$ to $7 \cdot 7 \%)$ and $4 \cdot 2 \%(2 \cdot 2 \%$ to $6 \cdot 1 \%)$ respectively. Figure 1 shows that all but one subject showed an increase in latency at $\mathrm{T} 12$ and that all showed an increase at $\mathrm{C} 7$. The changes in latency at T12 and C7 during the two years of follow up were significant $(p<0.0001)$. The latency of conduction through the spinal cord to the cortex remained unchanged.

The mean latencies of the positive peaks of the evoked potentials from the ankle to $\mathrm{T} 12$ and from the wrist to $\mathrm{C} 7$ and the changes over two years are shown in table III and figure 2. The conduction time in the median nerve from the wrist to Erb's point was

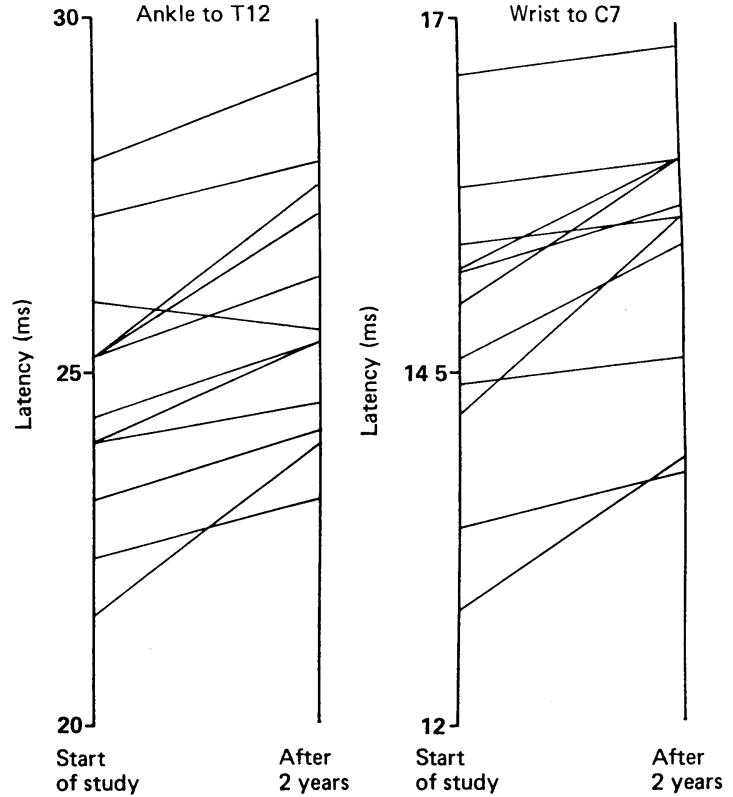

FIG 1-Latencies of somatosensory evoked responses from ankle to T12 and from wrist to $C 7$ in 12 men positive for HIV at start of study and after two years

increased in all subjects $(5 \cdot 6 \%(3 \cdot 7 \%$ to $7 \cdot 5 \%)$; $\mathrm{p}<0.0001$ ) whereas the conduction time from Erb's point to $\mathrm{C} 7$ was unchanged. Conduction in the tibial nerve increased by $2 \cdot 2 \%(-2 \cdot 7 \%$ to $7 \cdot 0 \%)$, but the change was not significant. The conduction time from the gluteal crease to $\mathrm{T} 12$ was, however, increased in all subjects, the average increase being $31 \cdot 7 \%(21 \cdot 4 \%$ to $42 \cdot 2 \%) ; \mathrm{p}<0.0001)$. The relative delay in conduction from the gluteal crease to $\mathrm{T} 12$ exceeded that in the tibial $(p<0.0001)$ and median nerves $(p<0.01)$ as well as that from Erb's point to $\mathrm{C} 7(\mathbf{p}<0.001)$ (fig 2$)$.

No relation was found between the increase in latency of the evoked somatosensory responses and the clinical stage of HIV infection, the duration of established HIV infection, and the counts of lymphocytes and $\mathrm{T}_{4}$ cells.

\section{Discussion}

Neurological manifestations are known to occur in a few subjects during latent HIV infection despite their preserved immune competence. We found that the

TABLE II-Conduction time and distance from ankle to T12 and from wrist to C7 with conduction time from T12 and C7 to cerebral cortex in 12 men positive for HIV at start of study and after two years. Values are means (SE) unless stated otherwise

\begin{tabular}{|c|c|c|c|c|c|c|}
\hline & \multicolumn{2}{|c|}{ Ankle to T12 } & \multicolumn{2}{|c|}{ Wrist to $\mathrm{C} 7$} & \multirow{2}{*}{$\begin{array}{l}\text { Conduction } \\
\text { time from T12 } \\
\text { to cortex (ms) }\end{array}$} & \multirow{2}{*}{$\begin{array}{l}\text { Conduction } \\
\text { time from C7 } \\
\text { to cortex (ms) }\end{array}$} \\
\hline & $\begin{array}{c}\text { Conduction time } \\
(\mathrm{ms})\end{array}$ & $\begin{array}{l}\text { Distance } \\
(\mathrm{cm})\end{array}$ & $\begin{array}{l}\text { Conduction time } \\
\text { (ms) }\end{array}$ & $\begin{array}{l}\text { Distance } \\
(\mathrm{cm})\end{array}$ & & \\
\hline Start & $24 \cdot 7(0.5)$ & $108 \cdot 6(1 \cdot 0)$ & $14.9(0.4)$ & $72 \cdot 7 \quad(1 \cdot 1)$ & $11 \cdot 4(0 \cdot 4)$ & $5 \cdot 6(0 \cdot 2)$ \\
\hline After 2 years & $26 \cdot 1(0 \cdot 5)$ & $108 \cdot 5(1 \cdot 0)$ & $15 \cdot 5(0 \cdot 3)$ & $72.5(1.4)$ & $11.0(0.4)$ & $5 \cdot 6(0 \cdot 1)$ \\
\hline Intraindividual change & $1.35(0.25)^{\star}$ & $-0.17(0.98)$ & $0.62(0.13)^{\star}$ & $-0.23(0.88)$ & $-0.42(0.32)$ & $-0.05(0.09)$ \\
\hline $95 \%$ Confidence interval & 0.80 to 1.90 & -2.32 to 1.99 & 0.33 to 0.91 & $-2 \cdot 18$ to $1 \cdot 72$ & $-1 \cdot 12$ to 0.29 & -0.26 to 0.15 \\
\hline
\end{tabular}

$\star \mathrm{p}<0 \cdot 0001$.

TABLE III -Conduction time and distance in four conduction segments after nerve stimulation at ankle and wrist with registration at gluteal crease, T12, Erb's point, and C7 in 12 men positive for HIV at start of study and after two years. Values are mean (SE) unless stated otherwise

\begin{tabular}{|c|c|c|c|c|c|c|c|c|}
\hline & \multicolumn{2}{|c|}{ Tibial nerve } & \multicolumn{2}{|c|}{ Gluteal crease to $\mathrm{T} 12$} & \multicolumn{2}{|c|}{ Median nerve† } & \multicolumn{2}{|c|}{ Erb's point to $\mathrm{C} 7$} \\
\hline & $\begin{array}{l}\text { Conduction time } \\
(\mathrm{ms})\end{array}$ & $\begin{array}{l}\text { Distance } \\
(\mathrm{cm})\end{array}$ & $\begin{array}{l}\text { Conduction time } \\
(\mathrm{ms})\end{array}$ & $\begin{array}{l}\text { Distance } \\
(\mathrm{cm})\end{array}$ & $\begin{array}{l}\text { Conduction time } \\
\text { (ms) }\end{array}$ & $\begin{array}{l}\text { Distance } \\
(\mathrm{cm})\end{array}$ & $\begin{array}{l}\text { Conduction time } \\
\text { (ms) }\end{array}$ & $\begin{array}{l}\text { Distance } \\
(\mathrm{cm})\end{array}$ \\
\hline Start & $13 \cdot 0(0 \cdot 4)$ & $71 \cdot 6(1 \cdot 1)$ & $6 \cdot 4(0 \cdot 2)$ & $36.3(0.9)$ & $9 \cdot 5(0 \cdot 2)$ & $62.6(1.4)$ & $3 \cdot 4(0 \cdot 2)$ & $5 \cdot 4(0 \cdot 1)$ \\
\hline After 2 years & $13 \cdot 3(0.4)$ & $72 \cdot 3 \quad(1 \cdot 4)$ & $8 \cdot 4(0 \cdot 3)$ & $36 \cdot 9(0 \cdot 7)$ & $10 \cdot 0 \quad(0 \cdot 2)$ & $62 \cdot 3(1 \cdot 1)$ & $3.3(0.3)$ & $5 \cdot 5(0 \cdot 1)$ \\
\hline Intraindividual charge & $0 \cdot 28(0 \cdot 29)$ & $0.67(0.81)$ & $2 \cdot 03(0 \cdot 30) \ddagger$ & $0.62(1 \cdot 24)$ & $0.53(0.08) \neq$ & $-0.27(1.79)$ & $-0.09(0.19)$ & \\
\hline $\begin{array}{l}95 \% \text { Confidence } \\
\text { interval }\end{array}$ & -0.35 to 0.91 & $-1 \cdot 11$ to $2 \cdot 45$ & 1.37 to $2 \cdot 70$ & $-2 \cdot 12$ to $3 \cdot 37$ & 0.35 to 0.71 & $-4 \cdot 27$ to $3 \cdot 72$ & -0.51 to 0.32 & \\
\hline
\end{tabular}




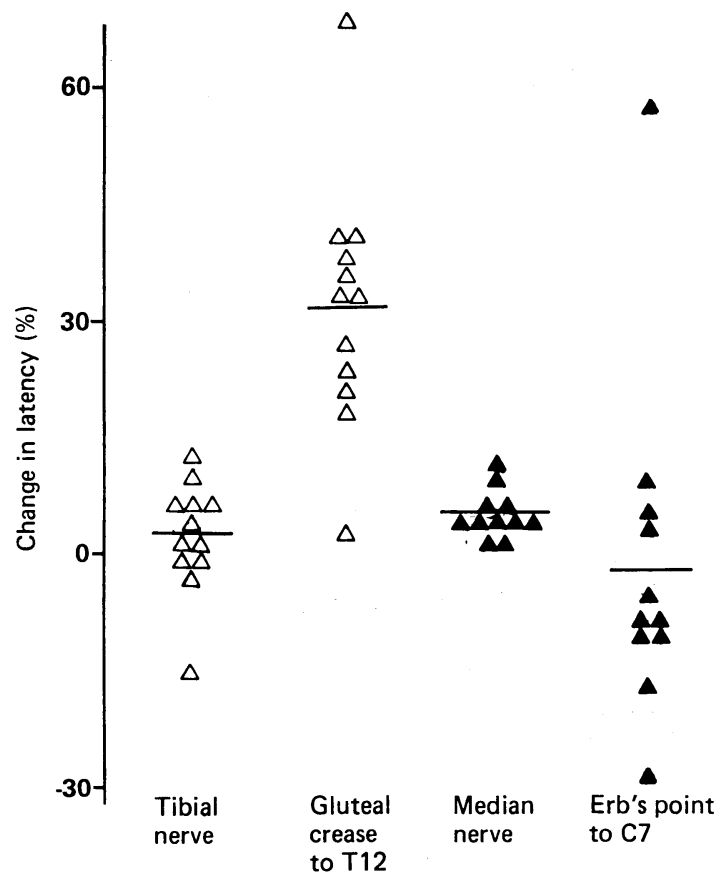

FIG 2-Changes in latency of somatosensory evoked responses over two years in 12 men positive for HIV in tibial nerve (ankle to gluteal crease), in segment from gluteal crease to T12, in median nerve (wrist to Erb's point) and in segment from Erb's point to C7. Horizontal bar indicate mean values in group

propagation of impulses through peripheral nerves into the spinal cord was impaired in all 12 of our subjects. This impairment occurred despite the fact that none had developed AIDS and that symptoms and signs of neurological disease were few. These observations suggest a close association between the HIV infection and an insidiously progressive neurological disorder.

Conduction time in the nervous system increases with age in healthy control subjects. Table IV shows mean values obtained in our laboratory in control subjects of the same age range as the men studied. According to these values, the latency of T12 should increase by $0.05 \mathrm{~ms}$ and the conduction velocities of the tibial and median nerve decrease by $0.2 \mathrm{~m} / \mathrm{s}$ over two years. Consequently, the influence of age amounts to less than $5 \%$ of the increase we observed in the conduction time in peripheral nerves.

Myelopathy and peripheral neuropathy often occur in AIDS. In a necropsy study $23 \%$ of patients had vacuolar myelin degeneration of the long tracts of the lumbar spinal cord.' A distal symmetrical polyneuropathy of the axonal type with a mild slowing of conduction velocity and reduced nerve action potentials was found in about a third of patients in hospital with AIDS. ${ }^{6}$ Our results show a silent peripheral neuropathy which seems to be concomitant with the HIV infection. The conduction velocity of large myelinated fibres of the median nerve was reduced by $5.6 \%$ and occurred in all patients. The most pronounced impairment of conduction was found in the segment from the gluteal crease to the lumbar part of the spinal cord (T12). As no significant slowing occurred in the tibial nerve distal

TABLE IV-Conduction time and distance from ankle to T12 and from wrist to $C 7$ with conduction velocity in tibial and median nerves in 48 healthy control subjects aged 15-44. Values are means (SE)

\begin{tabular}{|c|c|c|c|c|c|c|}
\hline \multirow[b]{2}{*}{ Age (years) } & \multicolumn{2}{|c|}{ Conduction time $(\mathrm{ms})^{\star}$} & \multicolumn{2}{|c|}{ Distance $(\mathrm{cm})$} & \multicolumn{2}{|c|}{ Conduction velocity $(\mathrm{m} / \mathrm{s})$} \\
\hline & Ankle to $\mathrm{T} 12$ & Wrist to $\mathrm{C} 7$ & Ankle to $\mathrm{T} 12$ & Wrist to $\mathrm{C7}$ & Tibial nerve & Median nerve \\
\hline $15-24(n=10)$ & $24 \cdot 0(0 \cdot 6)$ & $14 \cdot 5(0 \cdot 1)$ & $111(1 \cdot 8)$ & $73(1 \cdot 4)$ & $57(1 \cdot 1)$ & $70(1 \cdot 8)$ \\
\hline $25-34(\mathrm{n}=21)$ & $24 \cdot 0(0 \cdot 3)$ & $14.5(0 \cdot 1)$ & $110(1 \cdot 4)$ & $74(0.9)$ & $56(0.9)$ & $67(0 \cdot 8)$ \\
\hline $35-44(\mathrm{n}=17)$ & $24.5(0.4)$ & $14.5(0 \cdot 1)$ & $110(1.9)$ & $74(1 \cdot 2)$ & $55(0.7)$ & $68(0 \cdot 7)$ \\
\hline
\end{tabular}

to the gluteal crease and conduction remained unchanged in the comparable segment from Erb's point to the spinal cord (C7) the observed conduction impairment could be due to a pathological process restricted either to the lumbar part of the spinal cord or to the lumbar roots.

Polyradiculopathy with subacute onset at the sacral and lumbar level and with pleocytosis in cerebrospinal fluid has been described in a few patients with AIDS. ${ }^{+11}$ A more slowly developing pathological process with or without the dorsal root ganglion being affected might underlie our electrophysiological results. Our studies in patients with AIDS showed, however, that electrophysiological abnormalities were also present in the thoracolumbar spinal cord towards the cortex from T12."

We suggest, therefore, that after the early attack at $\mathrm{T} 12^{8}$ a progressive lumbar spinal cord disorder develops during latent HIV infection and eventually leads to paresis and ataxia of the legs. ${ }^{912}$ Furthermore, our observation of a distal conduction defect in the upper extremity and of a proximal defect restricted to the lower extremity alone suggests that the myelo(radiculo)pathy and the peripheral neuropathy are independent lesions. The finding of a more pronounced increase in the latency of the positive peaks of evoked potentials compared with the negative peaks indicates that the largest nerve fibres are predominantly affected.

The roles of autoimmune mechanisms, nutritional deficiency, and direct viral infection in causing myelopathy and peripheral neuropathy are unknown. In a subgroup of patients with latent HIV infection and inflammatory demyelinating neuropathy the demyelination was mediated by macrophages. ${ }^{13}$ There is no evidence, however, that the slowly progressive axonal neuropathy found in a large proportion of patients with AIDS is due to a defect in cell mediated immunity.

Retroviruses are neurotropic and HIV viruses have been isolated from brain, spinal cord, peripheral nerves, and cerebrospinal fluid. ${ }^{14}$ Particles like HIV have been seen under the electron microscope in the axons of only one patient. ${ }^{15}$ In situ hybridisation, however, has shown no evidence of HIV genomes in peripheral nerve structures. ${ }^{13}$

In our patients high alcohol consumption and drug treatment did not cause neurotoxicity, and nutritional deficiency did not seem to have a role as the general condition of the men was good and they did not lose weight. The number of $\mathrm{T}_{4}$ lymphocytes decreased significantly, but only two patients had counts below $0 \cdot 3 \times 10^{9} / 1$. We found no relation between the number of $\mathrm{T}_{4}$ cells and electrophysiological impairment. Further studies are needed to clarify the role of latent HIV infection in the development of progressive myelo(radiculo)pathy and peripheral neuropathy. One possibility is that HIV itself causes the neurological dysfunction and that the development of symptoms such as immunodeficiency is mainly a function of time since infection. ${ }^{16}$

We thank Erna Petersen, Ingrid Lindquist, Birthe Nielsen, Karen Rasmussen, Jytte Schmidt, and Birte Winther for their technical help.

1 Snider WD, Simpson DM, Nielson S, et al. Neurological complications of acquired immune deficiency syndrome. Analysis of 50 patients. Ann Neurol acquired immune

2 Levy RM, Bredesen DE, Rosenblum ML. Neurological manifestations of the acquired immunodeficiency syndrome (AIDS): experience at UCSF and review of the literature. 7 Neurosurg 1985;62:475-95.

3 De la Monte SM, Gabuzda DH, Ho DD, et al. Peripheral neuropathy in the acquired immunodeficiency syndrome. Ann Neurol 1988;23:485-92.

4 Miller RG, Parry GJ, Pfaeff W, et al. The spectrum of peripheral neuropathy associated with ARC and AIDS. Muscle and Nerve 1988;11:857-63.

Cornblath DR, McArthur JC. Predominantly sensory neuropathy in patients with AIDS and AIDS-related complex. Neurology 1988;38:794-6.

6 So YT, Holtzman DM, Abrams DI, Olney RK. Peripheral neuropathy associated with acquired immunodeficiency syndrome. Prevalence and 
clinical features from a population-based survey. Arch Neurol 1988:45: 945-8.

7 Petiro CK, Navia BA, Cho E-S, at al. Vacuolar myelopathy pathologically resembling subacue combined degeneration in paients with the acelired immune deficiency syndrome. N Engl f Med 1985;312:874-9.

8 Smith T, Jakobsen J, Gaub J, et al. Clinical and electrophysiological studies of human immunodeficiency virus-seropositive men without AIDS. Ann Neurol 1988;23:295-97.

9 Helweg-Larsen S, Jakobsen J, Boesen F, et al. Myelopathy in AIDS: A clinical and electrophysiological study of 23 patients. Acta Neurol Scand 1988;77:64-73.

10 Centers for Disease Control. Classification system for human T-lymphotropic virus type III/lymphadenopathy-associated virus infections. MMWR 1986;35:334:9.

11 Eidelberg D, Sotrel A, Vogel H, et al. Progressive polyradiculopathy in acquired immune deficiency syndrome. Neurology 1986;36:912-6.
12 Navia BA, Jordan BD, Price RW. The AIDS dementia complex. I. Clinical features. Ann Neurol 1986;19:517-24.

13 Cornblath DR, McArthur JC, Kennedy PGE, et al. Inflammatory demyelinating peripheral neuropathies associated with human T-cell lymphotropic linating peripheral neuropathies associated with hum
virus type III infection. Ann Neurol 1987;21:32-40.

14 Ho DD, Rota TR, Schooley RT, et al. Isolation of HTLV-III from cerebrospinal fluid and neural tissues of patients with neurological syndromes related to the acquired immunodeficiency syndrome. $N$ Engl $f$ Med 1985:313:1493-7

15 Bailey RO, Baltch AL, Venkatesh R, et al. Sensory motorneuropathy associated with AIDS. Neurolog 1 1988;38:886-91.

16 Polk BF, Fox R, Brookmeyer R, et al. Predictors of the acquired immunodeficiency syndrome developing in a cohort of seropositive homosexual men. N Engl F Med 1987;316:61-6.

Accepled 24 April 1989

\title{
Influence of maternal diet during lactation and use of formula feeds on development of atopic eczema in high risk infants
}

\author{
Ranjit Kumar Chandra, Shakuntla Puri, Azza Hamed
}

\begin{abstract}
Objective-To examine the effects of maternal diet during lactation and the use of formula feeds on the development of atopic eczema in infants at risk.

Design-Mothers who planned to breast feed exclusively were randomly allocated to either a restricted diet (avoiding milk and other dairy products, eggs, fish, peanuts, and soybeans) or a diet without restrictions. Mothers who did not plan to breast feed were randomly allocated to using one of three formula feeds.

Setting - Child health centre in Canada.

Subjects -97 Mothers who chose to breast feed and 124 mothers who did not.
\end{abstract}

Interventions - Restricted diet for $\mathbf{4 9}$ mothers who breast fed. Casein hydrolysate formula, soy milk formula, or cows' milk formula for infants not breast fed.

Main outcome measure-Development of eczema in babies.

Results - Infants were followed up over 18 months and examined for eczema. Eczema was less common and milder in babies who were breast fed and whose mothers were on a restricted diet $(11 / 49(22 \%) v$ $21 / 48(48 \%))$. In infants fed casein hydrolysate, soy milk, or cows' milk 9/43 (21\%), 26/41 (63\%), and $28 / 40$ (70\%), respectively, developed atopic eczema.

Conclusions - In families with a history of atopic eczema mothers who breast feed should avoid common allergenic foods during lactation. If they choose not to breast feed a hydrolysate formula should be used.

\section{Introduction}

Atopic disorders include eczema, asthma, and rhinitis. These are common causes of childhood illness and visits to doctors. The enormous costs, both measurable (visits to the doctor, admissions to hospital, laboratory tests, medicines, special diets) and immeasurable (emotional stress, lost school days, social isolation), of managing children with atopic eczema have led to attempts at prevention. Food allergy, such as hypersensitivity to cows' milk, is an important contributory factor in atopic eczema ${ }^{1}$ and occurs commonly during early life. ${ }^{2}$ Allergic reactions to foods peak in infancy, and the prevalence tends to decrease with age. ${ }^{3}$ Although breast feeding affords partial protection, ${ }^{4-6}$ the occurrence of serious atopic disease even among exclusively breast fed children ${ }^{7}$ prompted us to suggest that sensitisation to food antigens may occur in utero and through breast milk. ${ }^{90}$ Several data support this concept. ${ }^{10-13}$ In view of these observations we conducted a randomised study to evaluate the role of maternal diet during lactation and of special infant formulas in preventing atopic eczema in infants at high risk.

\section{Subjects and methods}

In cases in which either of the baby's parents had a family history of atopic disease mothers were asked whether they planned to breast feed exclusively. They were contacted in antenatal clinics or a few days before or immediately after delivery in the two maternity hospitals in the city. About $85 \%$ of those eligible agreed to take part in the study. Staff in the labour room and nursery were instructed on the need for ensuring exclusive breast feeding. If the mothers intended to breast feed the study was explained to them, and they were randomised (based on a random number table) into either the experimental or the control group. Those in the experimental group were asked to observe dietary restrictions (exclusion of milk and other dairy products, eggs, fish, peanuts, and soybeans) for six months or the duration of lactation, if shorter than six months. They were advised to take $1 \mathrm{~g}$ of calcium supplement daily. Compliance was assessed by examining their daily diaries of foods consumed, direct questioning, and testing by enzyme linked immunoassay (ELISA) for $b$ lactoglobulin and ovalbumin in random samples of breast milk. Mothers who elected not to breast feed were given one of three coded formulas: conventional cows' milk (Enfalac), soy milk (Prosobee), and casein hydrolysate (Nutramigen). All three formulas are manufactured by Mead Johnson Canada. Formula feed was given on demand and ad libitum. Each infant received the assigned formula for at least six months. A physician examined the infants at $2,4,6,12$, and 18 months or more often if asked by the mother. The minimum follow up was 18 months in each case. The mothers and the observer were not aware of the type of formula given.

Atopic eczema was diagnosed if physical examination showed areas of scaly, erythematous, and itchy rash primarily of the face, the scalp, behind the ears, and the flexural folds. An eczema score, based on the system devised by Dr David Atherton, Hospital for Sick Children, Great Ormond Street, London, was calculated. ${ }^{10}$ The score is based on the distribution $(20$ parts of the body), type (erythema, scaling, lichenification), and severity (score 0 to 3 ) of skin disease. The maximum possible score is 180 .

The breast fed and formula fed groups were analysed 